\title{
ANALISIS FAKTOR PENYEBAB KECELAKAAN \\ PADA RUAS JALAN TANJUNG SERDANG-STAGEN KABUPATEN KOTABARU
}

\author{
Adhi Surya, Abdurrahman dan Buzman \\ Program Studi Teknik Sipil Fatek Uniska MAB \\ E-mail: adhisurya1998@gmail.com/HP.+6287782738533
}

\begin{abstract}
ABSTRAK
Kecelakaan lalu lintas sangat sering terjadi dan banyak menimbulkan kerugian. Akibat dari kecelakaan lalu lintas berupa kerusakan terhadap fasilitas-fasilitas umum dan timbulnya korban yang meninggal dunia. Kecelakaan lalu lintas dapat terjadi akibat dari faktor manusia. Kemungkinan penyebab kecelakaan adalah kelalaian dari manusia itu sendiri. Kelalaian yang menimbulkan kecelakaan lalu lintas, misalnya pengemudi kehilangan konsentrasi, lelah dan mengantuk, pengaruh alkohol dan obat, kecepatan melebihi batas atau ugal-ugalan, kondisi kendaraan bemotor yang kurang baik serta kurang pahamnya pengemudi tentang aturan berlalu lintas. Tujuan penelitian ini adalah menganalisis faktor penyebab kecelakaan dengan menggunakan data dari Polres Kotabaru dan dengan survei langsung kelapangan di ruas Jalan Tanjung Serdang-Stagen Kabupaten Kotabaru. Metode yang digunakan adalah campuran kuantitatif-kualitatif-deskriptif. Dengan tahapan survei, pengambilan data primer dari hasil pengukuran langsung di lapangan (Wawancara) dan data sekunder didapatkan dari Polisi Resort Kota (Polresta) Kabupaten Kotabaru dan Badan Pusat Statistik (BPS) Kabupaten Kotabaru, analisis data dengan melakukan analisis Black Spot dan melihat faktor dominan penyebab kecelakaan, lalu dibahas hasilnya dan disimpulkan. Berdasarkan analisis dapat disimpulan yaitu titik Black Spot pada ruas jalan tanjung serdang-stagen sebanyak 3 titik sepanjang $29 \mathrm{~km}$ yaitu di km 9-10,20-21 dan 26-27. Dimana pada ruas jalan ini kecelakaan disebabkan karena kelalaian pengendara dan terlalu cepat mengendarai kendaraan, di samping itu faktor umur juga menyebabkan terjadinya kecelakaan.
\end{abstract}

Kata Kunci: Analisis Faktor Penyebab Kecelakaan, Metode Campuran Kuantitaf Kualitatif Deskriptif, Ruas Jalan Tanjun Serdang-Stagen Kotabaru.

\section{ABSTRACT}

Traffic accidents are very frequent and cause many losses. As a result of traffic accidents in the form of damage to public facilities and the emergence of victims who died. Traffic accidents can occur due to human factors. The possible cause of the accident is negligence of the man himself. Negligence that causes traffic accidents, for example the driver loses concentration, is tired and drowsy, the influence of alcohol and drugs, speed exceeds the limit or is reckless, the condition of motorbikes is not good and the driver does not understand the rules of the traffic. The purpose of this study was to analyze the causes of accidents using data from the Kotabaru Police and a direct survey of the area on Jalan Tanjung Serdang-Stagen, Kotabaru Regency. The method used is a mixture of quantitative-qualitative-descriptive. With the survey stage, primary data collection from direct measurements in the field (Interviews) and secondary data were obtained from the City Police (Polresta) of Kotabaru Regency and the Central Statistics Agency (BPS) of Kotabaru Regency, data analysis by conducting Black Spot analysis and see the dominant factors causing the accident, then discuss the results and conclude. Based on the analysis, it can be concluded that the Black Spot points on the Tanjung Serdang-Stagen road segment are 3 points along $29 \mathrm{~km}$, namely at km 9-10,20-21 and 26-27. Where on this road, accidents are caused due to driver negligence and driving too fast, in addition, the age factor also causes accidents.

Keywords: Accident-Causing Factor Analysis, Descriptive Qualitative Quantitative Mixed Method, Tanjung Serdang-Stagen Kotabaru Road. 


\section{PENDAHULUAN}

\section{Latar Belakang}

Kecelakaan lalu lintas akhir-akhir ini sangat sering terjadi dan banyak menimbulkan kerugian. Akibat dari kecelakaan lalu lintas berupa kerusakan terhadap fasilitas-fasilitas umum dan timbulnya korban yang meninggal dunia. Kecelakaan lalu lintas dapat terjadi akibat dari faktor manusia. Kemungkinan penyebab kecelakaan adalah kelalaian dari manusia itu sendiri. kelalaian yang menimbulkan kecelakaan lalu lintas, misalnya pengemudi kehilangan konsentrasi, lelah dan mengantuk, pengaruh alkohol dan obat, kecepatan melebihi batas atau ugal-ugalan, kondisi kendaraan bemotor yang kurang baik serta kurang pahamnya pengemudi tentang aturan berlalu lintas. Berdasarkan Pasal 1 angka 24 UndangUndang No. 22 Tahun 2009 tentang Lalu Lintas dan Angkutan Jalan, mengungkapkan kecelakaan lalu lintas adalah suatu peristiwa di jalan yang tidak diduga dan tidak disengaja yang melibatkan kendaraan dengan dan/atau kerugian harta benda didalam Pasal 240 dan Pasal 241 Undang-Undang No. 22 Tahun 2009 tentang Lalu Lintas dan Angkutan Jalan yang mengatakan bahwa setiap korban kecelakaan lalu lintas berhak mendapatkan pertolongan pertama dan perawatan dalam rumah sakit terdekat sesuai dengan ketentuan peraturan perundang-undangan. Ruas jalan Tanjung Serdang - Stagen Sepanjang $29 \mathrm{~km}$ yang merupakan jalan poros provinsi dan jalan poros antar kabupaten Kotabaru dengan Kabupaten Tanah Bumbu, pada era 5 Tahun terakhir ini pada ruas jalan Tanjung Serdang Stagen ini berdasarkan data Ditlantas Polres Kabupaten Kotabaru cenderung sering mengalami kecelakaan di bandingkan di segmen jalan lain yang ada di kabupaten Kotabaru dan sebelumnya belum pernah ada penelitian yang menyangkut kecelakaan.

\section{Rumusan Permasalahan}

1. Dimana saja daerah rawan kecelakaan (Black Spot) pada Ruas Jalan Tanjung SerdangStagen Kabupaten Kotabaru ?

2. Apakah ada hubungannya kecelakaan dengan profesi, tingkat pendidikan, umur, kepemilikan SIM, dan jenis kelamin pengguna jalan?

3. Apakah ada hubungannya pertambahan jumlah penduduk terhadap terjadinya kecelakaan?

4. Apakah ada hubungannya kecelakaan dengan permukaan jalan yang rusak ?

5. Apakah ada hubungannya kecelakaan dengan kelalaian manusia (human error)?

6. Apakah terjadinya kecelakaan ada hubungannya dengan geometrik jalan dan pertambahan volume lalu lintas?

\section{Tujuan}

Secara umum tujuan dari penelitian ini adalah untuk mencari :

1. Lokasi daerah rawan kecelakaan (Black Spot).

2. Hubungan antara profesi, tingkat pendidikan, umur, kepemilikan SIM, dan jenis kelamin pengguna jalan terhadap terjadinya kecelakaan.

3. Hubungan antara pertambahan jumlah penduduk terhadap terjadinya kecelakaan.

4. Hubungan antara kerusakan permukaan jalan terhadap terjadinya kecelakaan.

5. Hubungan antara kelalaian manusia terhadap terjadinya kecelakaan.

6. Hubungan antara geometrik jalan dan pertambahan volume lalu lintas terhadap terjadinya kecelakaan.

\section{Batasan Masalah}

Berhubung ruang lingkup pada penelitian ini sangat luas, maka dalam pelaksanaannya penelitian ini di lakukan dengan pembatasan : 
1. Pada penelitian ini kecelakaan yang menjadi kajian studi adalah kecelakaan yang terjadi di daerah rawan kecelakaan terkhusus di ruas jalan tanjung serdang-stagen sepanjang $29 \mathrm{~km}$ dan di 3 Titik BS (Black Spot).

2. Data sekunder, di peroleh dari Kepolisian Lakalantas Polres Kotabaru berupa data kejadian kecelakaan khususnya di ruas jalan tanjung serdang-stagen sepanjang $29 \mathrm{~km}$, dari tahun 2014 sampai dengan tahun 2018.

3. Data sekunder, di peroleh dari Badan Pusat Statistik (BPS) Kabupaten Kotabaru berupa data jumlah penduduk dari tahun 2014 sampai dengan tahun 2018.

\section{Faktor Penyebab Kecelakaan}

\section{TINJAUAN PUSTAKA}

Menurut ADB (Asian Development Bank, 1996), kecelakaan lalu lintas sering terjadi di negara berkembang dari pada di negara maju, karena pada negara berkembang jumlah fasilitasnya belum memadai. Warpani (2002) menjelaskan bahwa khususnya di Indonesia penyebab utama besarnya angka kecelakaan lalu lintas adalah faktor manusia, baik karena kelalaian, keteledoran, ataupun kelengahan para pengemudi kendaraan maupun pengguna jalan lainnya dalam berlalu lintas.Tingginya angka kecelakaan lalu lintas dan besarnya biaya kerugian yang diakibatkan oleh banyaknya permasalahan yang dihadapi dalam peningkatan keselamatan lalu lintas dan angkutan jalan yang perlu mendapatkan penanganan yang serius, maka salah satu cara untuk menekan angka kecelakaan tersebut dengan mengaudit penyebab terjadinya kecelakaan.

\section{Karakteristik Geometrik Jalan}

Karakteristik geometrik jalan menurut manual kapasitas jalan di Indonesia (1997), meliputi :

1. Tipe jalan : berbagai tipe jalan mempunyai kinerja yang berbeda pada pembebanan lalu lintas tertentu, misalnya jalan terbagi dan tak terbagi, jalan satu arah.

2. Lebar jalur lalu lintas : kecepatan arus bebas dan kapasitas meningkat dengan pertambahan jalur bebas lalu lintas.

3. Kereb : kereb sebagai batas antara jalur lalu lintas dan trotoar sangat berpengaruh terhadap hambatan samping pada kapasitas dan kecepatan. Kapasitas jalan dengan kereb yang lebih kecil dari jalan dengan bahu. Selanjutnya kapasitas berkurang jika terdapat penghalang tetap dekat tepi jalur lalu lintas, tergantung apakah jalan mempunyai kereb atau bahu.

4. Bahu : jalan perkotaan tanpa kereb pada umumya mempunyai bahu pada kedua sisi jalur lalu lintasnya. Lebar dan kondisi permukaannya mempengaruhi penggunaan bahu, berupa penambahan kapasitas, dan kecepatan pada arus tertentu, akibat pertambahan lebar bahu terutama karena pengurangan hambatan samping yang disebabkan kejadian disisi jalan,seperti kendaraan angkutan umum berhenti, pejalan kaki dan sebagainya.

5. Median : median direncanakan dengan baik meningkatka kapasitas.

6. Alinemen jalan : lengkung horizontal dengan jari-jari kecil mengurangi kecepatan arus bebas. Tanjakan yang curam juga mengurangi kecepatan dengan arus bebas. Karena secara umum kecepatan arus bebas didaerah perkotaan adalah rendah maka pengaruh ini diabaikan.

\section{METODE PENELITIAN}

Penelitian ini menggunakan metode campuran kuantitatif kualitatif deskriptif karena ciricirinya bersifat hitungan atau angka untuk mengetahui sejauh mana besar kecelakaan yang terjadi di ruas Jalan Tanjung Serdang-Stagen ini, pengambilan data secara aktual yang dilakukan wawancara langsung (kualitatif) dengan pengguna jalan. Dari observasi lapangan Jalan Tanjung Serdang-Stagen Kotabaru mempunyai satu jalur dan dua arah tanpa median 
dengan lebar efektif 7 meter dan masing bahu jalan 0.5 meter kondisi gunung-gunung dan batuan keras. Data-data akurat serta lengkap yang dapat dijadikan sebagai acuan dalam pemecahan masalah. Data-data yang diperlukan berupa data primer dan skunder sebagai berikut :

1. Data primer ini adalah sumber data yang diperoleh secara langsung dengan survei di lapangan dan didapat dari hasil wawacara dengan pengendara, survei geometrik dan kerusakan jalan.

2. Data Sekunder diperoleh berupa data kejadian kecelakaan, data yang di peroleh dari Lakalantas Polres Kotabaru dan data penduduk dari Badan Pusat Statistik (BPS) Kabupaten Kotabaru

3. Data Sekunder berupa peta Ruas Jalan Tanjung Serdang-Stagen Kotabaru dari www.googlemap.com

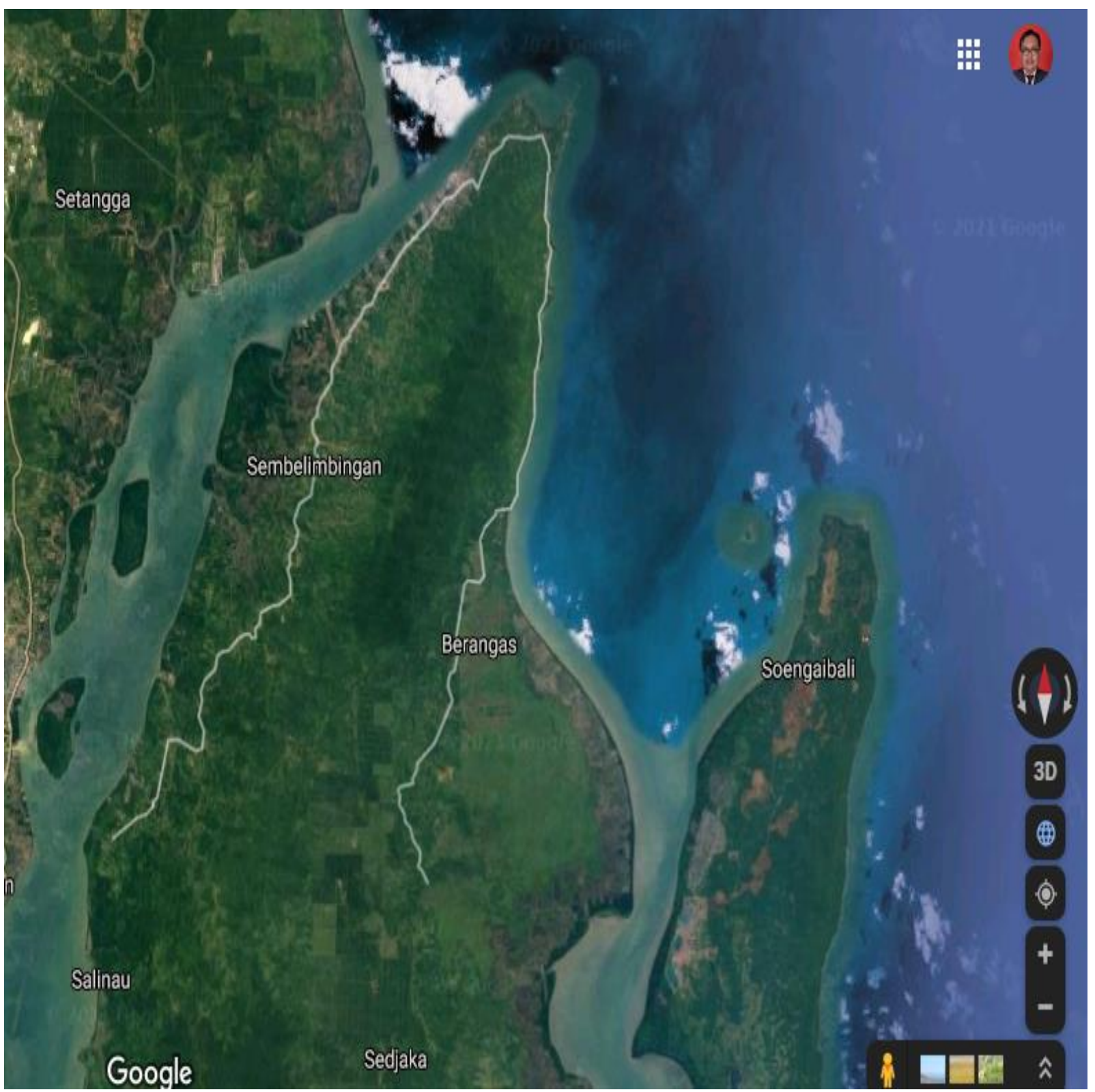

Gambar 1. Ruas Jalan Tanjung Serdang-Stagen Kotabaru Sumber : www.googlemap.com diakses 15 Januari 2021 


\section{HASIL DAN PEMBAHASAN}

Berdasarkan hasil persentase dari ke 6 (Enam) Nomor kuesioner dan masing-masing 10 lembar atau sepuluh orang setiap Blakc Spot maka sebagai berikut :

1. $100 \%$ Masyarakat menyatakan bahwa pada km 9-10, 20-21 serta km 26-27 adalah merupakan daerah rawan kecelakaan (Black Spot).

2. $87 \%$ Masyarakat menyatakan bahwa pada km 9-10, 20-21 serta km 26-27 kecelakaan di pengaruhi oleh Profesi, tingkat pendidikan, umur, kepemilikan SIM, dan jenis kelamin pengendara dan $17 \%$ yang menyatakan bahwa tidak ada kaitannya.

3. $87 \%$ Masyarakat menyatakan bahwa pada km 9-10, 20-21 serta km 26-27 kecelakaannya tidak dipengaruhi oleh pertambahan jumlah penduduk, dan hanya $13 \%$ yang berpendapat bahwa jumlah penduduk mempengaruhi kecelakaan yang terjadi.

4. $97 \%$ Masyarakat menyatakan bahwa pada km 9-10, 20-21 serta km 26-27 kecelakaannya tidak di pengaruhi oleh kerusakan permukaan jalan karena semua jalan di ruas jalan dan khususnya di 3 Blak Spot ini jalannya masih bagus, dan hanya $3 \%$ yang berpendapat bahwa kecelakaan akibat kerusakan permukaan jalan mempengaruhi kecelakaan yang terjadi dan kecelakaan bukan karena jalan yang rusak tetapi pengguna jalan yang terlalu cepat sehingga tidak terkendali.

5. Dan $7 \%$ Masyarakat menyatakan bahwa pada km 9-10, 20-21 serta km 26-27 terjadi karena faktor gaib dan $93 \%$ masyarakat yang menyatakan kecelakaan yang terjadi hanyalah kelalaian dari pengendara (ada yang jatuh pada saat dia masih dalam keadaan mabuk dan ada yang keadaan ngantuk dan lain sebagainya).

6. $90 \%$ Masyarakat menyatakan bahwa pada km 9-10, 20-21 serta km 26-27 kecelakaannya tidak di pengaruhi oleh kondisi geometrik jalan dan pertambahan volume lalu-lintas, $10 \%$ masyarakat berpendapat bahwa ada hubungannya karena kalau terjadi hujan jalan akan licin dan terkadang menyebabkan kecelakaan tetapi selain itu tidak ada.

\section{PENUTUP}

\section{Kesimpulan}

Dari banyak pertimbangan dan analisa serta pembahasan yang telah di sampaikan pada bagian sebelumnya dapat di tarik kesimpulan sebagai berikut :

1. Lokasi rawan kecelakaan di daerah jalan Tanjung Serdang-Stagen terdapat di daerah KM 910, 20-21 Dan 26-27 dan sebagai black spot.

2. Faktor tingkat umur mempengaruhi terjadinya kecelakaan dari data kepolisian kabupaten kotabaru yang sangat banyak adalah di umur 36-45 tahun yaitu berjumlah 12 orang dari total 31 orang kecelakaan selama 5 tahun.

3. Faktor tingkat profesi mempengaruhi terjadinya kecelakaan dari data kepolisian kabupaten kotabaru yang sangat banyak adalah profesi pekerjaan karyawan swasta yaitu berjumlah 16 orang dari total 38 orang kecelakaan selama 5 tahun.

4. Faktor jenis kelamin mempengaruhi terjadinya kecelakaan dari data kepolisian Kabupaten Kotabaru yang sangat banyak adalah jenis kelamin laki-laki yaitu berjumlah 26 orang dari total 27 orang kecelakaan selama 5 tahun.

5. Faktor tingkat pendidikan mempengaruhi terjadinya kecelakaan dari data kepolisian kabupaten kotabaru yang sangat banyak adalah yang putus sekolah yaitu berjumlah 12 orang dari total 25 orang kecelakaan selama 5 tahun.

6. Faktor kepemilikan SIM tidak mempengaruhi terjadinya kecelakaan. 
7. Pertambahan volume arus lalu lintas tidak mempengaruhi terjadinya kecelakaan pada ruas jalan Tanjung Serdang-Stagen Kabupaten Kotabaru dimana kecelakaan yang sangat dominan adalah pada jam 12.00-13.00.

8. Geometrik jalan dan kerusakan jalan pada ruas jalan Tanjung Serdang-Stagen Kabupaten Kotabaru sesuai hasil data kuesioner yang didapatkan dari wawancara masyarakat adalah tidak mempengaruhi terjadinya kecelakaan.

9. Faktor kelalaian manusia (human error) sangat mempengaruhi terjadinya kecelakaan di ruas jalan Tanjung Serdang-Stagen Kabupaten Kotabaru.

\section{Saran}

Dari banyak pertimbangan dan analisis serta pembahasan yang telah disampaikan dan disimpulkan maka disarankan perlu mencari solusi mengukur variable-variabel berupa faktor penyebab kecelakaan dengan menggunakan statistika regresi berganda terhadap kecelakaan. Sehingga akan bisa diterima dengan baik argument ilmiahnya.

\section{DAFTAR PUSTAKA}

1. Dephub, (2015) Rekayasa Lalulintas, Direktorat Jendral Perhubungan Darat, Jakarta.

2. Dadans, S.(2001) Analisa Kecelakaan dan Kereta Api di DAOP VIII Surabaya.Tesis Program Pasca Sarjana MRT ITS, Surabaya.

3. Beni, S.D. (2001) Analisa Faktor Kecelakaan Dalam Upaya Peningkatan Keselamatan Lalulintas Bagi Pemakai jalan Tol Surabaya - Gempol, Tesis Program Pasca Sarjana MRT ITS, Surabaya.

4. Muhammad, S. (2015) Analisis Faktor Penyebab Kecelakaan Lalulintas di Ruas Jalan Poros Samarinda - Anggana, Universitas 17 Agustus 1945

5. Integrated Road Management System (IRMS)

6. Sukirman, (1999) Dasar-Dasar Perencanaan Geometrik Jalan, Bandung

7. Direktorat Pengembangan Jalan Kota, Manual Kapasitas Jalan Indonesia (MKJI) phase IV 1997, Direktorat Jendral Bina Marga Departemen Pekerjaan Umum RI 